Research Article

\title{
Autonomy, Acceptance and Utilization of NPCC: An Indian Scenario
}

\author{
Chandni', Urmila D Bharadwaj', Eke Lama Tamang 3 , Naseem Mancheri ${ }^{4}$ \\ ${ }^{1}$ M.Sc. Nursing Student, ${ }^{2}$ Professor, ${ }^{3}$ Assistant Professor, ${ }^{4}$ Tutor, Rufaida College of Nursing, Jamia Hamdard, New Delhi, India. \\ DOI: https://doi.org/10.24321/2455.9318.202004
}

I $\quad \mathbf{N} \quad \mathbf{F} \quad \mathbf{O}$

Corresponding Author:

Chandni, Rufaida College of Nursing, Jamia

Hamdard, New Delhi, India.

E-mail Id:

bhilwarachandni@yahoo.com

Orcid Id:

https://orcid.org/0000-0003-0842-1136

How to cite this article:

Chandni, Bharadwaj UD, Tamang EL, Mancheri N. Autonomy, Acceptance and Utilization of NPCC: An Indian Scenario. Int J Nurs Midwif Res 2020; 7(1): 18-23.

Date of Submission: 2020-04-24

Date of Acceptance: 2020-06-18
$\begin{array}{llllllll}\mathbf{A} & \mathbf{B} & \mathbf{S} & \mathbf{T} & \mathbf{R} & \mathbf{A} & \mathbf{C} & \mathbf{T}\end{array}$

Introduction: It is very evident that Nurse Practitioners (NPs) are the need of the hour. As demand for NPs in all types of intensive care units continues to increase; ensuring successful integration of these nurses into general and specialty intensive care units poses several challenges. Multiple quantitative studies revealed the attributes of NPs', practice, autonomy and roles. However, researcher has not come across any study to assess the acceptability, autonomy \& utilization of Nurse Practitioner in Critical Care (NPCCs) among health care professionals and other stakeholder.

Methods: A quantitative approach descriptive research design was adopted to assess the acceptability, autonomy and utilization of NPCCs among healthcare professionals and stakeholders of selected institutes of India. The present study was conducted among 35 NPCCs, 15 physicians and 80 other healthcare professionals through purposive Sampling techniques. Five point Likert scale was used to assess the acceptability, autonomy and utilization of NPCCs and an expressed practice checklist was used to assess the critical care skills and procedure performed by NPCCs after taking formal permission from the competent authority.

Result: Most of the physicians of selected institute refused to participated, only 15 were responded, indicated the less interest in this subject for them. Regarding acceptability the physicians who accepted the NPCCs were responded to the study and illustrated $100 \%$ of acceptance, (65\%) of the health care professionals and other stakeholders accepted NPCCs in critical care. More than half of the NPCCs (63\%) have expressed autonomy in performing their role in critical care .Regarding utilization of NPCCs (60\%) physicians like to utilize NPCCs in critical care whereas (40\%) been indecisive about the utilization of NPCCs in critical care. Majority of the health care professionals (excluding physician) and other stakeholders (79\%) like to utilize NPCCs in critical care, whereas (21\%) been indecisive about the utilization of NPCCs in critical care.

Conclusion: Nurse practitioners need to become more visible to both the public and other health care professionals. In spite of lot of challenges of NPCCs to get trained and work in India, health care professionals (excluding physicians) and other stakeholders had positive opinion towards the prospects of NPCCs, reflects their acceptance and the utilization for NPCCs in India.

Keywords: NPCC, Autonomy, Acceptability, Utilization, Health Care Professionals, Stakeholder 


\section{Introduction}

The role of the nurse practitioner was first introduced in the United States 'health care system in 1965 and the role of nurse practitioners in the Intensive Care Unit (ICU) has evolved considerably since the 1990s. ${ }^{2}$ After early descriptions of the role of these nurses in pediatric and adult ICUs, delineation of role development in a variety of critical care settings and recent descriptions of successful orientation programs, models of care, and evidence of positive outcomes for nurse practitioners have strengthened the value of having the practitioners on the critical care team. Today, the use of nurse practitioners as mid-level providers continues to grow and has become a positive force in providing health care in any settings. Despite the increasing prevalence of nurse practitioners, Edmunds writes that the nurse practitioner is still unknown to many as a member of the health care team. ${ }^{7}$ As per the information of American Association of Nurse Practitioners (AANP) in the year 2015 there are more than 278000 NPs licensed in U.S. about $95.7 \%$ of NPs prescribe medication and more in full time practice write an average of 20 prescription and majority around $57.4 \%$ see 3 or more patients per hour. Malpractice rates remain low, only $1.1 \%$. The Bureau of Labour Statistic estimates the NPs profession will have grown by $36 \%$ by 2026 , compared to $37 \%$ for physician (excluding anesthesiologists and surgeon). As AANP president Joyce Knestrick found that "couple with news that NPs conducted an estimated 1.02 billion patient visits last year alone, and its easy to see why millions of Americans are making NPs their providers of choice. ${ }^{18}$ Considering these findings and those of previous research, the nurse practitioner in Critical Care plays an important dimension in meeting today's health care needs. It has been estimated that $50 \%$ to $90 \%$ of the activities performed by physicians can be delegated to nurse practitioners. ${ }^{9}$ In 25 states, plus the District of Columbia, nurse practitioners can practice independently without physician collaboration or supervision, Several organizations have published reports of successful integration of NPs into care delivery models for ICU providers. ${ }^{10}$

In context of India, this program of NPCCs was under plan of Indian Nursing Council (INC) in the year of 2015 \& started by various colleges all over the country in the year 2017.1,4,5 It's just a beginning, there is long way to cover. The nurse practitioners in India are working under the title of staff nurses and do not have the authority to prescribe the drugs or practice independently. Nurse practitioners are educated in the advanced practice of nursing, which incorporates medical skills needed for curing while maintaining their nursing skills of caring. Nurse practitioners bring with them a holistic and humanistic, patient centered practice that incorporates health maintenance and promotion, patient education, counseling and advocacy. Despite mounting evidence of effectiveness as health care providers, nurse practitioners continue to struggle for professionals' acceptance. A major deterrent is a lack of understanding from health care professionals as well as the general public regarding the role of the nurse practitioner. Additional impediments include variations in education among nurse practitioners, consecutive concerns from physicians, legislative restrictions to practice, reimbursement policies and prescriptive authority controversies. Combinations of these Actions can result in the underutilization of nurse practitioner services. The continued successful merger of the nurse practitioner into the health care arena will largely depend on the understanding and acceptance of their role by physicians, other health care professionals, and patients. And the researcher has not come across with such study in India so far. There is a need for health care professional's awareness regarding the nurse practitioner in critical care \& their scope of practice. The present study aims to assess the acceptance, utilization and autonomy of the nurse practitioner in critical care among health care professionals and other stakeholders. Understanding of these three aspects is imperative in order to guide future education of the health care professionals and the ultimate goal of that education will be favorable integration and utilization of the nurse practitioner who can work independently in the critical care units at tertiary level with good team support.

\section{Material and Methods}

The research approach selected for the study was quantitative with descriptive survey research design. In the present study sample comprised of 35 NPCCs, 80 healthcare professionals (excluding physician) and 15 physicians of selected institutes from Uttar Pradesh, Uttarakhand, Madhya Pradesh and Punjab .Inclusion criteria were NPCCs who were placed in the same institute's hospital from where they took their training, Nurse who have practiced nursing for a minimum of 2 years, Health care professionals and other stakeholders in the hospitals where NPCC training provided.. The study excluded the NPCCs students in their $1^{\text {st }}$ year session and Healthcare professional who are not involved with NPCCs. The tool developed and used for data collection was five point Likert scale to assess the acceptability, autonomy and utilization of NPCCs among healthcare professionals (excluding physicians), stakeholders and physicians of selected institutes. Presently the prescription authority is given to only physician \& medical practitioners in the country hence a separate tool was prepared for the physicians apart from health care professional. To ensure the validity of tool, it was given to 7 experts from the field of Medicine, Psychiatry, Community Health Nursing, Critical care Nursing and reliability of the tool was established by using chronbach's alpha formula found to be 0.928 . The duration data were collected from October, 2019 to November, 2019of the study was one month . The subjects were visited only once to collect the data. The study was 
approved by Jamia Hamdard institutional ethical committee. A written informed consent was obtained from the subjects prior to the data collection. The data obtained was tabulated in Microsoft excel spreadsheet and was analyzed in terms of objectives of the study using descriptive and inferential statistics.

\section{Result}

Table I.Frequency and percentage of demographic variables of Nurse Practitioners in Critical Care

\begin{tabular}{|c|c|c|}
\hline Variables & Frequency (f) & Percentage (\%) \\
\hline \multicolumn{3}{|c|}{ Age (in years) } \\
\hline $25-30$ & 34 & 97.14 \\
\hline $31-35$ & 01 & 02.85 \\
\hline \multicolumn{3}{|l|}{ Gender } \\
\hline Male & 20 & 57.14 \\
\hline Female & 15 & 42.85 \\
\hline \multicolumn{3}{|c|}{ Average Monthly family income (Rs.) } \\
\hline Less than Rs.20,000 & 10 & 28.57 \\
\hline $20,001-30,000$ & 15 & 42.85 \\
\hline $30,001-40,000$ & 04 & 11.42 \\
\hline $40,001-50,000$ & 03 & 08.57 \\
\hline More than 50,000 & 03 & 08.57 \\
\hline \multicolumn{3}{|c|}{ Professional experience in critical care(in years) } \\
\hline $1-4$ & 32 & 91.42 \\
\hline $5-8$ & 02 & 05.71 \\
\hline$>12$ & 01 & 02.85 \\
\hline
\end{tabular}

Table 2.Frequency and Percentage Distribution of Demographic Data of Health Care Professionals (excluding physician), stakeholders and physicians

\begin{tabular}{|c|c|c|c|c|}
\hline \multirow[t]{2}{*}{ Variables } & \multicolumn{2}{|c|}{$\begin{array}{c}\text { Healthcare professionals(excluding } \\
\text { physicians) \& stakeholders }\left(n_{2}\right)\end{array}$} & \multicolumn{2}{|c|}{ Physicians $\left(n_{3}\right)$} \\
\hline & Frequency (f) & Percentage (\%) & Frequency (f) & Percentage (\%) \\
\hline \multicolumn{5}{|c|}{ Gender } \\
\hline Male & 31 & 38.75 & 08 & 53.33 \\
\hline Female & 49 & 61.25 & 07 & 46.66 \\
\hline \multicolumn{5}{|c|}{ Professional qualification } \\
\hline Diploma & 23 & 28.75 & 00 & 00 \\
\hline Graduate & 13 & 16.25 & 06 & 40.00 \\
\hline Post-graduate & 42 & 52.5 & 07 & 46.66 \\
\hline Doctorate & 02 & 02.5 & 02 & 13.33 \\
\hline \multicolumn{5}{|c|}{ Designation } \\
\hline Staff Nurses & 59 & 73.75 & 00 & 00 \\
\hline Hospital Administrators & 10 & 12.5 & 00 & 00 \\
\hline Nurse administrators & 11 & 13.75 & 00 & 00 \\
\hline Physician & - & - & 15 & 100 \\
\hline
\end{tabular}




\begin{tabular}{|c|c|c|c|c|}
\hline \multicolumn{5}{|c|}{ Professional experience in critical care(in years) } \\
\hline $1-4$ & 53 & 66.25 & 11 & 73.33 \\
\hline $5-8$ & 16 & 20.00 & 02 & 13.33 \\
\hline $9-12$ & 02 & 02.5 & 00 & 00 \\
\hline More than 12 & 09 & 11.25 & 02 & 13.33 \\
\hline
\end{tabular}

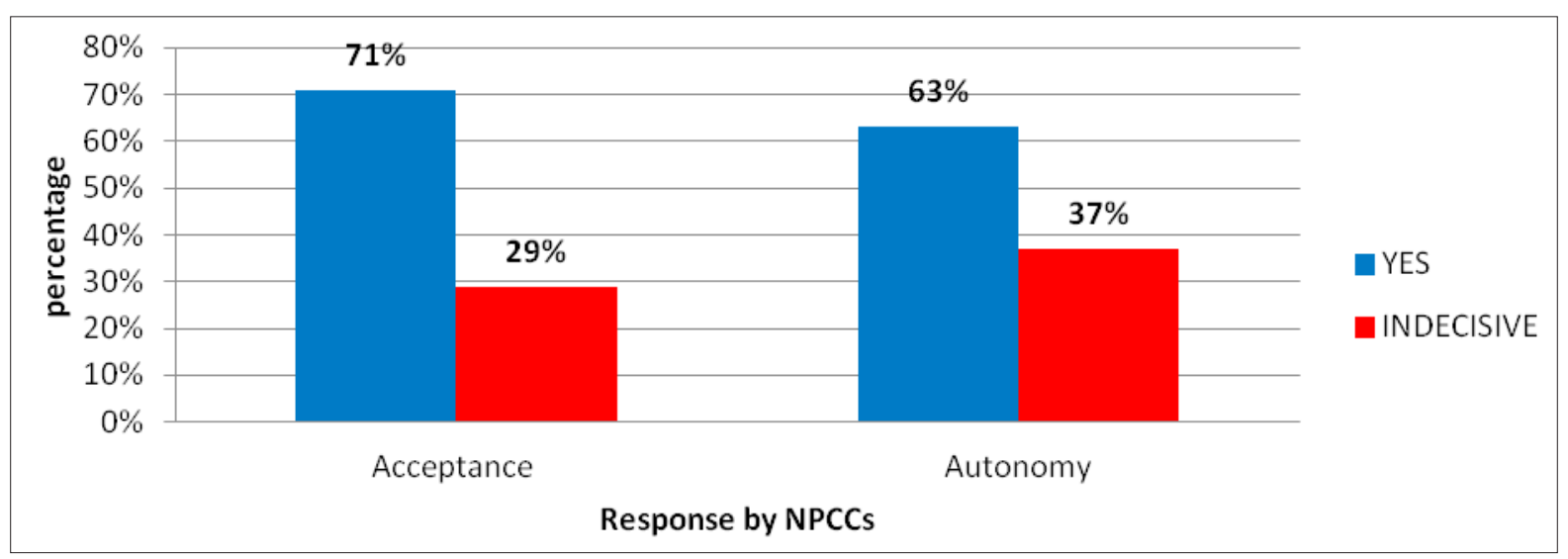

Figure I.Bar diagram showing the Percentage Distribution of Assessment of acceptability \& autonomy of NPCCs as per their response

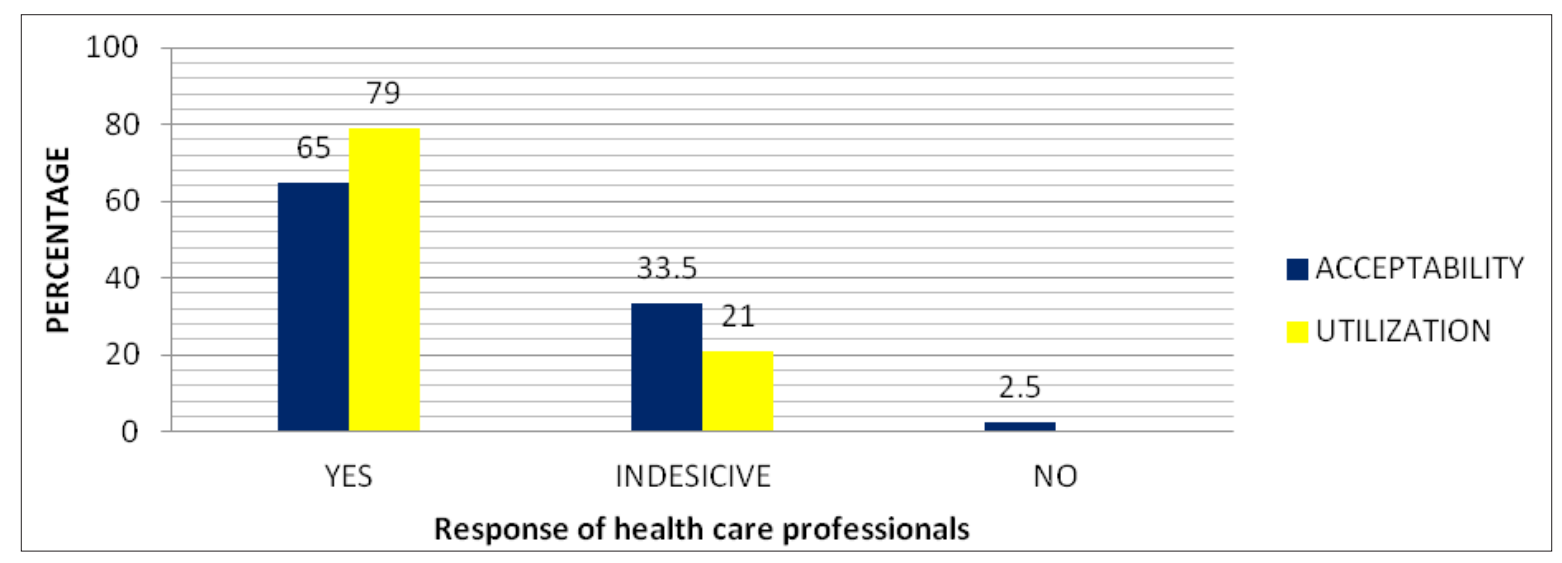

Figure 2.Bar diagram showing the percentage distribution of assessment of acceptability \& utilization of NPCCs by health care professionals (excluding physicians) and other stakeholders

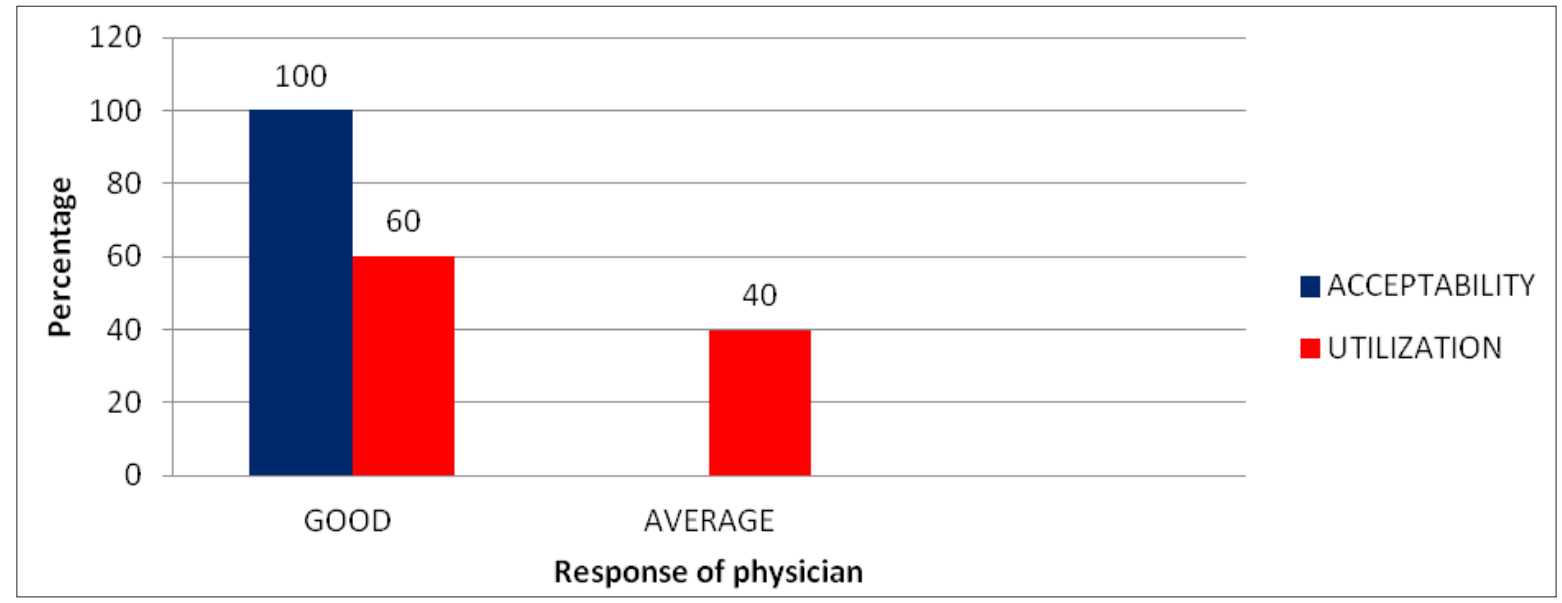

Figure 3.Bar diagram showing the Percentage Distribution of acceptability \& utilization Assessment of NPCCs by physicians 


\section{Discussion}

In the present study, 71\% NPCCs viewed themselves accepted in critical care while $29 \%$ was unsure about it .On ground of autonomy half of the samples $63 \%$ found high level of autonomy while working in ICU whereas 37 $\%$ were indecisive of it. The result of the study is similar to study conducted by K Sneha about ANPCC(Advance Nurse Practitioner In critical care ) program revealed that majority (96\%) of nursing personnel were aware of ANPCC, only $4 \%$ were not aware. (85\%) had positive opinion towards the prospects of ANPCC in India. (95\%) of nursing personnel opined that there is a great need of ANPCC in India and 92\% agreed that doctors needs to collaborate with the training of ANPCC. ${ }^{15}$ Hence, its shows that NPCCs is the need of the hour \& health care professional view NPCCs as a important member of the critical care team. INC, NPCCs Program will be for B.Sc nurses with a minimum of one year clinical experience which use competency based education that emphasizes clinical (80\%) supported by didactic course work (20\%). The two year program would lead to M.Sc. degree in critical care NP. ${ }^{5}$ The role of nurse practitioners is expanding; however, perceptions remain mixed regarding the scope of practice. One physician returned a tool with a saying "I feel if nurses want to practice medicine they should go to medical school." Attitudes such as these prevail, despite studies such as this one and the increasing of nurse practitioners in critical care. And on the other hand one physician respond very positively related to this issue, "I totally accepted the NPCCs but there is need to reconstruct the curriculum, their curriculum contain all the needed procedures but written haphazardly which need to be modify and this course required a specialized authority to trained the NPCCs \& NPCCs need to have broad base of knowledge \& competent enough to implement this course successfully". Most of the institutes don't grant the permission for conducting research study which shows lack of interest to the subject of study. In contrast state nursing council recognized institutions offering Nurse Practitioner in Critical Care (NPCC) programme, in academic year 2017-2018, there are 44 colleges are listed from all over India but half of institutes has less or no admission as per allotted seats to them, showing lack of awareness related to the course or people are already see the failure of NPs program in various other primary levels of the country. Despite the research finding this is the subjective feeling of the researcher that there is no separate cadre of nurse practitioner in critical care and no extra salary for NPCCs even though it is highly demanding area of practice considering a important factors contributing to no or less admission in this course of NPCC. The current Nursing Practice Act, 1947 does not have a provision for the advanced practice nurse or nurse practitioner title. There is no current legislature proposed that would create a defined advanced or independent nursing role. The Indian Nursing Council Act of 1947 Nurses in India does not have a defined scope of practice for the nurse nor the nurse practitioner. Regulation for the independent, nurse practitioner, or advanced nursing practice role does not exist. The proposed critical care NP role would prepare graduate nurses to work independently and collaboratively with per institutional protocols. The NP education includes courses in Advanced Pathophysiology, Advanced Pharmacology, and Advanced Health/ Physical Assessment, Nursing Research and Leadership. The critical care NP program would include a dissertation and criteria for research guides have been set. Nurses in India do not currently have prescriptive authority. Thus, autonomy is still a long way to lead.

\section{Conclusion}

Nurse practitioners need to become more visible to both the public and other health care professionals. Continuing to educate and expose the public and other health care professionals to nurse practitioners will influence perceptions which, in turn, may increase interest in learning more about the role and affect acceptance of the role and utilization of the nurse practitioner in critical care.The utilization of NPCCs continues to have much room for expansion, allowing NPs more autonomy and involvement in the care of critical care patients, if is important for physicians and other health care providers to be familiar with the capabilities of a NPCCs in order for them to be utilized to their maximum potential.

\section{Acknowledgement}

I appreciate the encouragement and support extended by my teachers for providing the inspiration, constant support, prayers and encouragement throughout the study. I express my whole hearted thanks to them.

\section{Conflict of Interest: None}

\section{References}

1. Anand S, Fan V. The health workforce in India. World Health Organization. 2016. Avaliable from: http://www. who.int/hrh/resources/16058health_workforce_India. pdf.

2. Sharma DC. India still struggles with rural doctor shortages. The Lancet 2015; 386(10011): 2381-2382.

3. World Health Organization [WHO]. 2016. The 2016 update, Global Health Workforce Statistics. Geneva http://www.who.int/hrh/statistics/hw.

4. Prashanth M. Enhancing the autonomy of Indian nurses. Indian J Med Ethics 2017; 2(4): 275-281.

5. Indian Nursing Council [INC] (2016). Syllabus \& Regulations; Nurse practitioner in critical care post graduate residency program. http://www. indiannursingcouncil.org/pdf/syllabusregulations.

6. Nanda L, Lobo E. Nurse Practitioners - India's Answer 
to Addressing Access to Healthcare. Public H Open Acc 2018; 2(2): 1-4.

7. Simone S, Carmel A. McComiskey, Brooke Andersen. Integrating Nurse Practitioners into intensive care units. crit care med 2016; 36(6): 59-68. http://dx.doi. org/10.4037/ccn2016360

8. American Association of Colleges of Nursing. Outstanding dissertation and DNP Project awards. 2015.

9. Denicola L, Kleid D, Brink L. Use of pediatric physician extenders in pediatric and neonatal intensive care units. Crit Care Med 1994; 22(11): 1856-1864.

10. Canadian Association of Critical Care Nurses. Position statement: Nurse practitioner in critical care. Dynamics, 2011; 22(1): 12-13.

11. Bambini, Deborah R. Nurse/Physician Perceptions of the Nurse Practitioner Role. Masters Theses 1995; 222. http://scholarworks.gvsu.edu/theses/222

12. James B, Marta T, Ines F, Luis L, Gilles D. Nurses in advanced roles: a review of acceptability in Portugal, Rev. Latino-Am.Enfermagem 2013; 21(Spec): 38-46. Available from www.eerp.usp.br/rlae.

13. Chiayi C, Donna R, McNeese S, Marie C, Valda U, Abdelmonem A. Evaluation of a Nurse Practitioner- Led Care Management Model in Reducing Inpatient Drug Utilization and Cost. Nursing economics 2009; 27(3).

14. Ruth K, Ward NS, Lynn A, Fred P, Douglas H. Provider to Patient Ratios for Nurse Practitioners and Physician Assistants in Critical Care Units. AJCC 2015; 24:(3). http://dx.doi.org/10.4037/ajcc2015274.

15. Leigh BP. Feasibility And Acceptability Of Nurse Practitioner-Led Student Health Services On A Regional Campus Published by ProQuest LLC. University of South Carolina 2018: 1-70.

16. Lusine P, Jianfang L, Jingjing $S$, Thomas DA. Practice environments and job satisfaction and turnover intentions of nurse practitioners: Implications for primary care workforce capacity. Health Care Manage Rev 2016; 10(1097): 1-10.

17. Krishnan S. A descriptive survey to assess the opinion of nursing personnel regarding the prospects and challenges of advance nurse practitioner in critical care in India in selected college and hospitals of Delhi. Masters Theses. 2018.

18. Gretch D. Advanced practice nursing and the role of the pediatric critical care nurse practitioner. crit care $q$ 1999; 21(4): 16-21.

19. Catherine M. Policies that restrict full utilization of nurse practitioners in primary care nursing economic. 2017; 35(2): 71-99.

20. Bnana L. trauma nurse practitioners variations in utilization and role expansion: jtn: 10,1097 www.journal of traumanursing.com. 